\title{
Pertumbuhan dan Produksi Tanaman Kentang (Solanum tuberosum L. var. Granola) pada Sistem Budidaya yang Berbeda
}

\section{The Growth and Production of Potatoes (Solanum tuberosum L. var. Granola) on Different System of Cultivation}

\author{
Partiyani Hidayah $^{1 *}$, Munifatul Izzati ${ }^{2}$, Sarjana Parman $^{2}$ \\ ${ }^{1)}$ Program Studi Biologi, Departemen Biologi, Fakultas Sains dan Matematika, Universitas Diponegoro \\ ${ }^{2)}$ Departemen Biologi, Fakultas Sains dan Matematika, Universitas Diponegoro \\ Jl. Prof. Soedarto, SH, Tembalang, Semarang \\ *Email : partiyaniumi@gmail.com
}

Diterima 27 Juni 2017 / Disetujui 28 Agustus 2017

\begin{abstract}
ABSTRAK
Kentang merupakan tanaman semusim yang penting dan memiliki potensi untuk diekspor ke negara lain serta banyak digunakan sebagai sumber karbohidrat atau makanan pokok bagi masyarakat dunia setelah gandum, jagung dan beras. Kentang sebagian besar dibudidayakan pada tanah yang miring dan di lahan yang memacu erosi tanah sehingga dapat menimbulkan tanah longsor. Hal ini disebabkan karena cara budidaya dengan penggemburan tanah sehingga tanah akan mudah lepas. Oleh karena itu, perlu dilakukan metode budidaya dalam polybag. Tujuan penelitian ini untuk mengkaji penanaman kentang di polybag dan lahan dalam meningkatkan pertumbuhan dan produksi kentang serta mengkaji perbedaan pertumbuhan dan produksi kentang yang ditanam dalam planterbag, polybag dan di lahan. Parameter yang diamati yaitu tinggi tanaman, jumlah daun, jumlah tunas yang tumbuh, jumlah umbi dan bobot umbi serta morfologi umbi. Perlakuan dilakukan dengan penanaman umbi kentang pada lahan, polybag dan planterbag atau 3 perlakuan dan 7 ulangan. Data penelitian dianalisis dengan Analysis of Variance (ANOVA) pada taraf kepercayaan 95\% dan dilanjutkan dengan Uji Beda Nyata Terkecil (BNT). Hasil analisis menunjukkan bahwa penanaman kentang dalam tempat penanaman yang berbeda dapat meningkatkan pertumbuhan dan produksi tanaman kentang dibandingkan dengan yang di lahan, meskipun yang berbeda nyata hanya tinggi tanaman dan jumlah daun. Kentang yang ditanam dalam polybag menghasilkan pertumbuhan yang lebih baik seperti tinggi tanaman, jumlah daun, dan jumlah tunas demikian juga dengan bobot umbinya dibandingkan dengan planterbag dan lahan. Sedangkan kentang yang ditanam di dalam planterbag menghasilkan jumlah umbi yang lebih banyak dibandingkan dengan polybag dan lahan. Budidaya tanaman kentang di dalam Polybag layak dilakukan karena dapat meningkatkan pertumbuhan dan produksi kentang varietas Granola.
\end{abstract}

Kata kunci: pertumbuhan, produksi, kentang, polybag.

\begin{abstract}
Potatoes are an important annual crop and have the potential to be exported to other countries and widely used as a source of carbohydrates or staple foods for the world community after wheat, corn and rice. Potatoes are mostly cultivated on sloping soils and on land that spur soil erosion that may cause landslides. This is because the way of cultivation with soil moisture so that the soil will easily escape. Therefore, a cultivation method is needed in the container. The purpose of this study is to examine potato cultivation in containers and land to improving potato growth and production as well as assessing differences in potato growth and production grown in containers of planterbag, polybag and on the land. Parameters observed were plant height, number of leaves, number of buds growing, morphology of tubers, tuber number and tuber weight. The treatment is done by planting potato tuber on the land, polybag and planterbag or 3 treatments and 7 replications. Data was analyzed by Analysis of Variance (ANOVA) at 95\% confidence level and continued with the test of the Least Significant Difference (LSD). The results showed that potato cultivation in containers could increase the growth and production of potato crops compared to those in the field, although only significantly different plant height and number of leaves. Potatoes grown in polybags produce better growth such as plant height,
\end{abstract}


leaf number, and number of shoots as well as tuber weight compared to planterbag and land. While the potatoes grown in the planterbag produce more tubers than the polybag and the land. The cultivation of potato plants inside the container is feasible because it can increase the growth and production of varieties of Granola.

Keywords: growth, production, potatoes, containers.

\section{PENDAHULUAN}

Kentang merupakan tanaman semusim yang memiliki potensi untuk diekspor ke negara lain. Tanaman ini termasuk tanaman pangan utama keempat dunia, setelah padi, gandum dan jagung (Asgar, 2013). Kentang dapat digunakan sebagai sayur maupun olahan dalam bahan baku industri misalnya potato chip/keripik (Prahardini dan Pratomo, 2011), pakan dan berpotensi untuk biofarmaka (Wattimena, 2000). Salah satu kentang yang banyak dibudidayakan di Indonesia yaitu kentang varietas Granola yang biasanya dimanfaatkan sebagai kentang sayur. Menurut Setiadi (2009), kentang varietas Granola memiliki kualitas mutu yang unggul karena produktivitasnya dapat mencapai 30-35 ton/ha. Selain itu, Granola tahan terhadap serangan penyakit, dapat dipanen dalam waktu 80 hari dan sering dijadikan sebagai sayur maupun bahan baku industri untuk keripik.

Menurut Badan Pusat Statistik (2016), luas panen kentang tahun 2014 adalah 76.291 ha, produksinya 1.347 .815 ton dengan produktivitas sebesar 17,67 ton/ha. Sedangkan luas panen kentang tahun 2015 yaitu 66.983 ha, produksinya 1.219.269 ton dengan produktivitas sebesar 18,20 ton/ha. Berdasarkan data tersebut, produktivitas kentang di Indonesia masih sangat rendah. Menurut FAO pada tahun 2015 produksi kentang di dunia masih didominasi oleh negara-negara subtropis seperti Amerika Serikat yang produktivitasnya sebesar 38,43 ton/ ha, Belanda sebesar 37,80 ton/ha, Selandia Baru sebesar 35,21 ton/ha, dan Jepang sebesar 32,69 ton/ha.

Menurut hasil Survei Sosial Ekonomi Nasional (2013), periode tahun 2002-2012, konsumsi rumah tangga kentang rata-rata meningkat sebesar $1,76 \%$ setiap tahunnya. Peningkatan terbesar terjadi di tahun 2007 naik sekitar 25\% dibandingkan tahun sebelumnya. Sebaliknya penurunan terbesar terjadi pada tahun 2009 sebesar 15,38\%. Tahun 2012 konsumsi kentang sebesar $1,460 \mathrm{~kg} / \mathrm{kapita} / \mathrm{tahun}$ atau turun sebesar 6,67\% dibandingkan tahun 2011. Tahun 2013 sedikit meningkat yaitu sebesar $1,40 \%$ dari tahun 2012 atau menjadi sekitar 1,480 $\mathrm{kg} / \mathrm{kapita} / \mathrm{tahun}$ dan tahun 2014 konsumsi kentang sama dengan tahun sebelumnya yaitu sekitar 1,480 $\mathrm{kg} / \mathrm{kapita/tahun}$.

Kentang pada umumnya dibudidayakan di daerah dataran tinggi dengan kemiringan tertentu yang dapat menimbulkan erosi dan tanah longsor. Upaya yang dapat dilakukan untuk mengurangi dampak negatif dari budidaya kentang pada dataran tinggi di lahan yang miring yaitu dengan budidaya kentang dalam Polybag. Budidaya di dalam Polybag dapat dilakukan dengan menggunakan polybag maupun planterbag. Polybag memiliki ketahanan bahan 2-3 tahun dengan warna hitam yang dapat memberikan suasana gelap didalam media dan dapat merangsang pertumbuhan dan perkembangan akar tanaman (Wasonowati, 2011), sedangkan planterbag memiliki ketahanan bahan sampai 5 tahun dengan warna hijau yang dapat ditembus oleh cahaya matahari sehingga sirkulasi udara dan air di dalam media dapat terjadi secara lancar dan tanaman dapat tumbuh lebih sehat dan subur (Lestari, 2015).

Cara budidaya kentang dengan penggemburan tanah sehingga tanah akan mudah lepas. Oleh karena itu, perlu dilakukan budidaya dalam Polybag sehingga tidak menyebabkan penggemburan tanah dan peristiwa tanah longsor. Penelitian ini bertujuan untuk mengukur pertumbuhan dan produksi hasil panen kentang yang ditanam dalam polybag dan planterbag dengan yang di lahan.

\section{METODE PENELITIAN}

Penelitian ini dilaksanakan di kebun pekarangan rumah Dusun Jurang, Desa Bedono, Kecamatan Jambu. Waktu pelaksanaan penelitian dimulai pada bulan Januari 2017 hingga April 
2017. Peralatan yang digunakan dalam penelitian meliputi tampah, cangkul, crengkeng, karung, tali rafia, ember ukuran 5 liter dan 2 liter, penggaris, meteran, kayu atau bambu, timbangan, kamera dokumentasi, buku dan alat tulis. Bahan yang digunakan untuk penelitian berupa tanaman kentang (Solanum tuberosum L. var. Granola), polybag, planterbag, pupuk kandang, tanah, dan air. Penelitian ini menggunakan 3 (tiga) perlakuan. Perlakuan yang diberikan adalah P0 pada tanaman yang dibudidayakan pada lahan. P1 untuk tanaman yang dibudidayakan dalam planterbag serta P2 untuk tanaman yang dibudidayakan dalam polybag. Setiap perlakuan diulang sebanyak 7 kali ulangan. Perlakuan diberikan selama 11 minggu dengan pengamatan dan pengukuran setiap satu minggu sekali. Pengamatan penelitian ini memiliki beberapa parameter yang meliputi tinggi tanaman, jumlah daun, jumlah tunas yang tumbuh, hasil umbi (jumlah dan bobot umbi), serta bentuk morfologi umbi. Data yang diperoleh kemudian dianalisis dengan Analysis of Variance (ANOVA) pada taraf kepercayaan $95 \%$ untuk pembuktian hasil, berpengaruh nyata atau tidak. Jika terdapat beda nyata dilanjutkan dengan uji Beda Nyata Terkecil (BNT) pada taraf kepercayaan $95 \%$.

\section{HASIL DAN PEMBAHASAN}

Hasil analisis perlakuan polybag, planterbag dan lahan pada tanaman kentang varietas Granola terhadap pertumbuhan tinggi tanaman dan jumlah daun dengan Analysis of Variance (ANOVA) menunjukkan hasil yang berbeda nyata sedangkan jumlah tunas yang tumbuh tidak berbeda nyata $(\mathrm{P}>$ 0,05 . Hasil uji lanjut dengan uji BNT (Beda Nyata Terkecil) menunjukkan terdapat perbedaan nyata antara perlakuan lahan terhadap polybag dan planterbag sedangkan perlakuan polybag tidak berbeda nyata dengan planterbag. Hal ini menunjukkan bahwa polybag dan planterbag mempengaruhi tinggi tanaman dan jumlah daun pada tanaman kentang varietas Granola. Rata-rata tinggi tanaman paling tinggi terdapat pada perlakuan polybag sebesar $435,03 \mathrm{~cm}$, selanjutnya perlakuan planterbag sebesar $380 \mathrm{~cm}$ dan lahan sebesar 264,76 cm. Rata-rata jumlah daun paling banyak pada perlakuan polybag yaitu sebesar 1089,4 helai daun, selanjutnya perlakuan planterbag sebesar 888 helai daun dan lahan sebesar 658,94 helai daun. Rata-rata jumlah tunas yang tumbuh paling banyak terdapat pada perlakuan polybag yaitu sebesar 10,61 tunas, selanjutnya planterbag sebesar 9,1 tunas dan lahan sebesar 8 tunas yang tumbuh.

Tabel 1. Hasil analisis rata-rata tinggi tanaman, jumlah daun, dan jumlah tunas yang tumbuh pada tempat penanaman yang berbeda

\begin{tabular}{cccc}
\hline \multirow{2}{*}{ Perlakuan } & \multicolumn{3}{c}{ Parameter } \\
\cline { 2 - 4 } & Tinggi tanaman & Jumlah daun & Jumlah tunas \\
\hline Polybag & $435,03^{\mathrm{a}}$ & $1089,40^{\mathrm{a}}$ & $10,61^{\mathrm{a}}$ \\
Planterbag & $380^{\mathrm{a}}$ & $888^{\mathrm{a}}$ & $9,10^{\mathrm{a}}$ \\
Lahan & $264,76^{\mathrm{ab}}$ & $658,94^{\mathrm{ab}}$ & $8^{\mathrm{a}}$ \\
\hline
\end{tabular}

Keterangan : Angka yang ditujukkan dengan superskrip yang sama pada kolom yang sama menunjukkan perbedaan tidak nyata $(\mathrm{P}>0,05)$.

Rata-rata tinggi tanaman, jumlah daun dan jumlah tunas yang tumbuh paling tinggi terdapat pada perlakuan polybag. Hal ini disebabkan oleh terpenuhinya kebutuhan unsur hara di dalam polybag yang mampu diserap langsung oleh akar tanaman kentang tanpa menyebar dan berkompetisi dengan tanaman yang lainnya. Menurut Pracaya (2007), penanaman kentang didalam polybag memiliki keuntungan yaitu pupuk yang mudah diserap langsung oleh akar tanaman sehingga kebutuhan unsur hara mineral dan air dapat dipenuhi secara optimal dan efisien. Wasonowati (2011) menyatakan bahwa, polybag memiliki bahan yang berwarna hitam dengan suasana gelap di dalam media tanam yang mampu merangsang pertumbuhan dan perkembangan akar tanaman, dimana akar yang tumbuh dengan baik akan menyerap unsur hara dan mineral di dalam tanah 
sehingga pertumbuhan tanaman juga akan meningkat dan lebih subur.

Jumlah tunas yang banyak akan mempengaruhi pertumbuhan tanaman yang lain seperti tinggi tanaman dan jumlah daun serta produktivitas tanaman juga akan meningkat. Menurut Zelelew (2016), tanaman yang lebih tinggi akan mempunyai produksi daun per tanaman yang lebih banyak dan akan mempengaruhi produksi dari fotosintat. Jumlah tunas yang dihasilkan oleh tanaman dalam jumlah yang banyak, maka tanaman akan mempunyai kanopi yang menutupi tanah lebih awal sehingga tanaman akan tumbuh lebih tinggi untuk mendapatkan lebih banyak cahaya matahari dalam melakukan proses fotosintesis.

Hasil uji Analysis of Variance (ANOVA) menunjukkan bahwa perlakuan lahan, polybag dan planterbag tidak berpengaruh nyata terhadap jumlah tunas dari tanaman kentang varietas Granola yang berarti bahwa perlakuan tidak mempengaruhi jumlah tunas yang tumbuh dari umbi kentang yang ditanam dan yang mempengaruhi pertumbuhan tunas adalah faktor lingkungan berupa kondisi iklim dengan curah hujan yang tinggi, sehingga umbi akan mudah menjadi busuk dan pertumbuhan tunasnya terhambat. Sunarjono (2007), menyatakan bahwa keadaan iklim yang ideal untuk tanaman kentang adalah suhu rendah (dingin) dengan suhu rata-rata harian antara $15-20^{\circ} \mathrm{C}$. Kelembaban udara 80- 90\% cukup mendapat sinar matahari (moderat) dan curah hujan antara 200-300 mm per bulan atau rata-rata $1000 \mathrm{~mm}$ selama pertumbuhan.

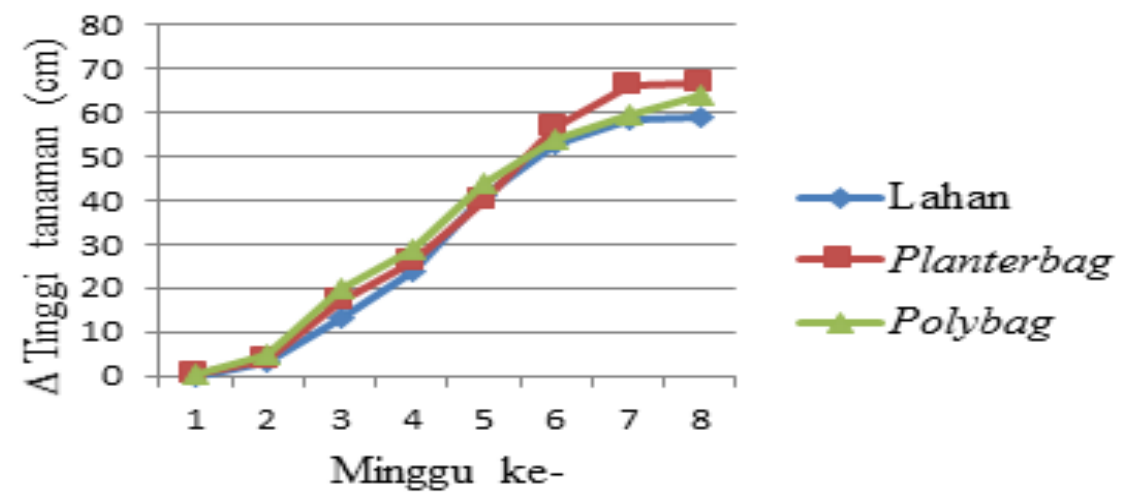

Gambar 1. Rata-rata tinggi $(\mathrm{cm})$ tanaman kentang varietas Granola pada perlakuan lahan, polybag dan planterbag

Berdasarkan hasil pengamatan dan pengukuran terhadap tinggi tanaman kentang varietas Granola tersebut terlihat bahwa pada minggu ke-1,6,7, dan 8 rata-rata tinggi tanaman paling tinggi pada planterbag sedangkan minggu ke-2,3,4, dan 5 pada polybag. Hal ini menunjukkan bahwa kentang yang ditanam dalam planterbag dan polybag mengalami peningkatan tinggi tanaman yang lebih baik dibandingkan dengan di lahan. Zulfitri (2015), menyatakan bahwa pengaruh peningkatan tinggi tanaman berkaitan dengan penambahannya jumlah dan ukuran sel. Pertumbuhan tinggi tanaman menunjukkan aktivitas pembentukan xilem dan pembesaran selsel yang tumbuh. Aktivitas ini menyebabkan kambium terdorong keluar dan terbentuknya sel-sel baru di luar lapisan-lapisan tersebut sehingga terjadi peningkatan tinggi tanaman. Menurut Lestari (2015), planterbag dapat ditembus cahaya matahari dan didesain dengan tambahan lubang drainase yang akan membantu sirkulasi udara dan air sehingga tanaman memiliki sistem perakaran yang kuat dan sehat serta tanaman dapat tumbuh lebih subur dan sehat. Wasonowati (2011), menyatakan bahwa polybag merupakan kantong dari plastik berwarna hitam yang memiliki lubang aerasi pada bagian dasar hingga $3 / 4$ tinggi polybag yang berfungsi mengatur suhu media agar tidak terlalu panas dan mengalirkan kelebihan air atau sisa pemupukan dengan lancar dan cepat sehingga drainase dan aerasinya optimal yang menyebabkan tanaman mampu tumbuh dengan baik dengan peningkatan pertumbuhan yang signifikan. 
Puncak tertinggi dari tinggi tanaman kentang pada minggu ke-8 dan mengalami penurunan pada minggu ke-9 hingga minggu ke-11 karena banyak tanaman yang layu dan mati. Laju pertumbuhan tanaman kentang akan menurun jika telah berada pada fase penuaan dan pertumbuhan umbi hingga puncak tanaman mati dan siap untuk dipanen. Menurut Oliveira (2015), pada fase pertumbuhan umbi terjadi persaingan yang kuat antara umbi dengan bagian atas tanaman yang sama-sama tumbuh dan sama-sama berperan sebagai penerima (sink). Persaingan itu berhenti setelah pertumbuhan bagian atas tanaman mencapai maksimum dan hanya umbi yang berfungsi sebagai penerima, sedangkan bagian atas tanaman berubah menjadi sumber.

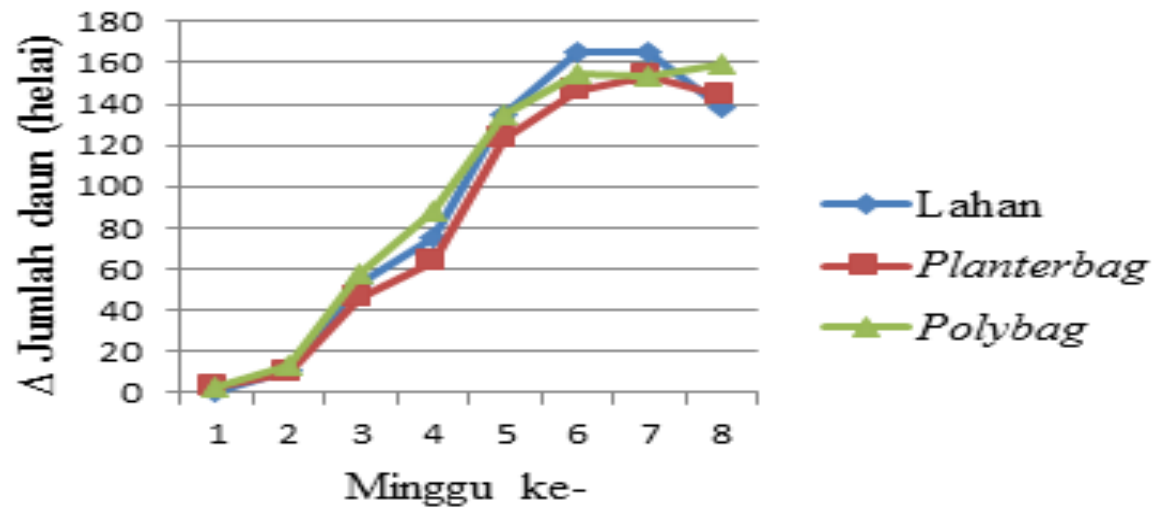

Gambar 2. Grafik $\Delta$ rata-rata jumlah daun tanaman kentang varietas Granola pada perlakuan lahan, polybag dan planterbag

Berdasarkan hasil pengamatan terhadap jumlah daun tanaman kentang varietas Granola tersebut terlihat bahwa pada minggu ke-1 jumlah daun paling banyak pada planterbag, minggu ke-2, $3,4,5$, dan 8 pada polybag dan minggu ke- 6 dan 7 pada lahan. Polybag mempunyai jumlah daun yang lebih banyak karena memiliki jumlah anakan yang lebih tinggi dengan pertumbuhan tinggi tanaman yang lebih baik. Selain itu, nutrisi dan hara yang terdapat dalam polybag mampu diserap oleh umbi kentang untuk menghasilkan jumlah daun yang banyak. Menurut Wiratama (2016), tanaman yang ditanam dalam polybag memiliki ketahanan yang lebih bagus dibandingkan tanaman yang ditanam dengan media yang lainnya, karena pemeliharaa tanaman dapat dilakukan secara individu dan nutrisi yang diberikan dapat langsung diserap oleh akar. Selain itu, polybag sangat baik untuk drainase dan aerasi sehingga tanaman yang ditanam dalam Polybag akan lebih subur dan menghasilkan jumlah daun pertanaman yang lebih banyak.

Jumlah daun yang banyak dipengaruhi oleh jumlah anakan atau tunas yang tumbuh dan tinggi tanaman. Menurut Zelelew (2016), tanaman yang lebih tinggi akan mempunyai produksi daun per tanaman yang lebih banyak dan akan mempengaruhi produksi dari fotosintat. Jumlah daun pada perlakuan lahan mengalami penurunan pada minggu ke-7 hingga minggu ke-8, planterbag pada minggu ke-8 sedangkan polybag pada minggu ke-7 dan mengalami peningkatan pada minggu ke8. Penurunan jumlah daun disebabkan oleh adanya fase penuaan dan pembentukan umbi pada tanaman kentang sehingga tanaman mulai layu, daun gugur dan mati. Menurut Solin (2009), fase penuaan dicirikan oleh laju pertumbuhan yang menurun, saat tumbuhan sudah mencapai kematangan dan mulai menua. Zulkarnain (2010), menyatakan bahwa pada fase pemasakan umbi terjadi perubahan warna vena daun yang menguning kemudian daunnya rontok, fotosintesis menurun, pertumbuhan umbi melambat dan vena-vena daun akhirnya mati.

Berdasarkan hasil pengamatan terhadap jumlah tunas atas yang tumbuh tanaman kentang varietas Granola tersebut terlihat bahwa pada minggu ke-1 jumlah tunas paling banyak pada planterbag sedangkan minggu ke-2, 3, 4, 5, 6 dan 7 pada polybag. Pada polybag jumlah tunasnya paling tinggi karena nutrisi dan unsur hara mampu diserap langsung oleh akar tanaman kentang tanpa menyebar dan berkompetisi dengan tanaman yang lainnya. Menurut Mulyono (2016), komposisi media tanam berupa tanah dan penutrisian dapat diatur sendiri pada polybag sehingga tanaman akan memperoleh nutrisi yang optimal serta mempermudah penyerapan nutrisi oleh akar tanaman karena nutrisi-nutrisi tersebut hanya terfokus pada tanaman yang berada dalam polybag 
tersebut sehingga tanaman akan mengalami pertumbuhan yang optimal untuk meningkatkan jumlah tunas yang tumbuh.

Setelah minggu ke-7 jumlah tunas yang tumbuh mengalami penurunan karena tanaman banyak yang layu dan mati. Oliveira (2015), menyatakan bahwa laju pertumbuhan tunas bergantung pada suhu dan kelembaban serta akan menurun pada fase pemasakan umbi. Pada fase pemasakan umbi pertumbuhan umbi dan tunas akan melambat dan menurun hingga tanaman yang berada di atas permukaan tanah layu dan mati.

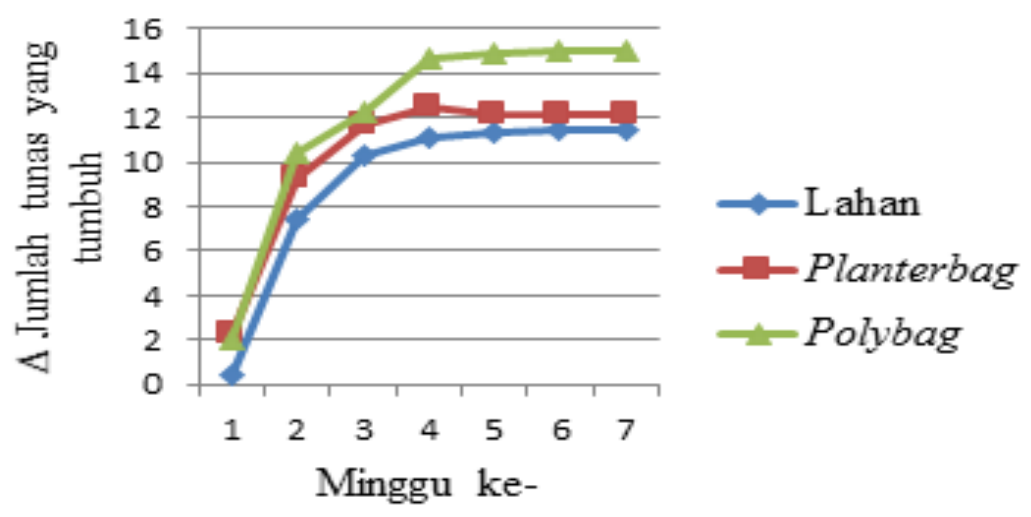

Gambar 3. Grafik $\Delta$ rata-rata jumlah tunas atas yang tumbuh tanaman kentang varietas Granola pada perlakuan lahan, polybag dan planterbag

Tabel 2. Hasil analisis rata-rata jumlah umbi dan bobot umbi pada tempat penanaman yang berbeda

\begin{tabular}{ccc}
\hline \multirow{2}{*}{ Perlakuan } & \multicolumn{2}{c}{ Parameter } \\
\cline { 2 - 3 } & Jumlah umbi & Bobot Umbi \\
\hline Polybag & $17,57^{\mathrm{a}}$ & $228,57^{\mathrm{a}}$ \\
Planterbag & $18,71^{\mathrm{a}}$ & $207,14^{\mathrm{a}}$ \\
Lahan & $14,57^{\mathrm{a}}$ & $185,71^{\mathrm{a}}$ \\
\hline
\end{tabular}

Keterangan : Angka yang ditujukkan dengan superskrip yang sama pada kolom yang sama menunjukkan perbedaan tidak nyata $(\mathrm{P}>0,05)$.

Hasil uji Analysis of Variance (ANOVA) menunjukkan bahwa perlakuan polybag, planterbag dan lahan tidak berpengaruh nyata terhadap jumlah umbi dan bobot umbi dari tanaman kentang varietas Granola ( $\mathrm{P}>0,05)$. Prematilake (2005) menyatakan bahwa air yang terlalu banyak tidak hanya menyebabkan masa panen jadi lebih lama, tetapi juga menyebabkan umbi yang dihasilkan sedikit, terkadang bahkan tidak membentuk umbi. Lestari et al., (2015) menambahkan bahwa, umbi yang terbentuk pun akan cepat membusuk. Tanaman yang tidak terkena sinar matahari menyebabkan aktivitas fotosintesis terhambat. Akibatnya, luas daun menjadi lebih kecil, daun cenderung melipat, buku menjadi rapat, dan tanaman menjadi tidak berbunga. Terhambatnya pertumbuhan tanaman menyebabkan umbi yang dihasilkan lebih sedikit dan berukuran lebih kecil.

Hasil penelitian menunjukkan bahwa ratarata kecenderungan jumlah umbi hasil panen yang paling tinggi pada perlakuan planterbag yaitu sebesar 18,71 umbi sedangkan polybag sebesar 17,57 umbi dan lahan 14,57 umbi. Jumlah umbi kentang yang paling banyak terdapat pada planterbag karena memiliki keunggulan dalam membantu proses transportasi dan penyimpanan zat makanan pada tanaman untuk menghasilkan umbi yang lebih tinggi. Menurut Lestari (2015), planterbag juga akan menghemat pemakaian pupuk tanaman serta tepat sasaran pemupukannya dibandingkan jika ditanam langsung pada kebun atau ladang, jika merupakan tanaman buah atau umbi maka hasil panen akan tiga kali lebih banyak 
dan berkualitas dibandingkan tanaman yang dibudidayakan di lahan karena pupuk tidak akan terserap oleh tanaman yang lain.

Jumlah umbi yang di panen produksinya relatif rendah karena curah hujan yang tinggi. Menurut Mailangkay (2012), curah hujan yang tinggi dapat menggangu pembungaan, penyerbukan dan pembentukan umbi. Zulkarnain (2010), menambahkan bahwa kentang memerlukan penyinaran panjang (Long Day Plant) yang sangat penting untuk proses fisiologis tanaman dalam menghasilkan umbi yang optimal. Jumlah daun dan tunas dipacu oleh panjang hari penyinaran. Jumlah umbi akan mencapai kemasakan apabila kelembaban dan nutrisinya sesuai atau tersedia.

Rata-rata bobot umbi berdasarkan hasil panen yang paling tinggi pada perlakuan polybag yaitu sebesar 228,57 gram sedangkan planterbag sebesar 207,14 gram dan lahan 185,71 gram. Bobot umbi paling tinggi pada perlakuan polybag karena memiliki jumlah tunas yang banyak untuk dapat menghasilkan produksi umbi yang optimal. Selain itu, penyerapan nutisi dan hara mineral dalam polybag diperkirakan lebih optimal. Menurut Zelelew (2016), tanaman yang memiliki jumlah tunas dalam jumlah yang banyak maka akan mempengaruhi tinggi tanaman dan produksi dari fotosintat. Produksi fotosintat yang tinggi juga menguntungkan bagi tanaman untuk menghasilkan berat umbi yang lebih besar per tanaman sehingga menghasilkan total umbi yang lebih banyak.

Bobot umbi yang dihasilkan pada semua perlakuan kurang optimal karena pengaruh intensitas curah hujan yang tinggi sehingga bobot umbi tidak sejalan dengan pertumbuhan tanaman kentang. Menurut Arifin (2014), semakin tinggi tanaman akan menghasilkan fotosintat lebih banyak sehingga pembentukan umbi dan pengisian umbi menjadi lebih banyak. Peningkatan pembentukan dan pengisian umbi yang banyak akan menghasilkan jumlah umbi yang banyak dengan ukuran yang besar dan bobot produksi umbi total per tanaman yang besar.

Bentuk morfologi umbi dilakukan dengan pengamatan bentuk umbi dari kedalaman mata tunas dan jumlah mata tunas pada permukaan umbi. Kedalaman mata tunas pada umbi kentang varietas Granola dangkal sehingga kentang ini sering dimanfaatkan sebagai sayur maupun kentang goreng dan keripik kentang dalam bidang industri. Mata tunas yang dangkal ini menunjukkan bahwa kentang varietas Granola tahan terhadap serangan penyakit. Jumlah mata tunas bervariasi mulai dari 1 mata tunas hingga 11 mata tunas yang terlihat pada permukaan umbi dengan bentuk umbinya lonjong. Setiadi (2009), menyatakan bahwa umbi kentang memiliki morfologi bervariasi, dilihat dari bentuk warna kulit, warna daging, dan mata tunasnya. Bentuk umbi kentang varietas Granola yaitu lonjong atau oval dengan mata tunas yang dangkal, warna kulit umbi dan daging umbi kuning. Granola tahan terhadap penyakit kentang umumnya, apabila kentang varietas lain kerusakan terhadap penyakit dapat mencapai $30 \%$ tetapi Granola hanya $10 \%$.

\section{KESIMPULAN}

Polybag dan planterbag cenderung dapat meningkatkan pertumbuhan dan produktivitas tanaman kentang dibandingkan dengan yang di lahan. Kentang yang ditanam dalam polybag cenderung menghasilkan pertumbuhan yang lebih baik seperti tinggi tanaman, jumlah daun, dan jumlah tunas demikian juga dengan bobot umbinya dibandingkan dengan planterbag dan lahan. Selain itu, polybag dan planterbag cenderung menghasilkan umbi lebih tinggi daripada di lahan.

\section{DAFTAR PUSTAKA}

Arifin, M.S., A. Nugroho dan A. Suryanto. 2014. Kajian Panjang Tunas dan Bobot Umbi Bibit terhadap Produksi Tanaman Kentang (Solanum tuberosum L.) Varietas Granola. Jurnal Produksi Tanaman 3 (2): 222.

Asgar, A. 2013. Umbi Kentang (Solanum tuberosum L.) Klon 395195.7 dan CIP 394613.32 yang ditanam di Dataran Medium mempunyai Harapan untuk Keripik. Balai Penelitian Tanaman Sayuran, Bandung.

Badan Pusat Statistik. 2016. Luas, Produksi dan Produktivitas Hortikultura Indonesia, Jakarta.

Cahyono, B. 2006. Teknik Budidaya dan Analisis Usaha Tani Kentang. CV Aneka Ilmu, Semarang. 
Lestari, P. 2015. The Best Growing Solution : Easy Grow Planter Bag. PT Wanghort Pratama, Tangerang.

Lestari, P., N.W. Utami, dan N. Setyowati. 2015. Peningkatan Produksi dan Perbaikan Ukuran Umbi Kentang Hitam (Plectranthus rotundifolius (Poir.) Spreng) melalui teknik Budidaya sebagai Upaya Konservasi. Lembaga Ilmu Pengetahuan Indonesia, Bogor 2 (18): 65-78.

Mailangkay, B.H., J.M Paulus dan J.X Rogi. 2012. Pertumbuhan dan Produksi Dua Varietas Kentang (Solanum tuberosum L.) pada Dua Ketinggian Tempat. Balai Pengawasan dan Sertifikasi Benih Tanaman Pangan dan Hortikultura, Sulawesi Utara 2 (18): 167169.

Muchjidin, R. 2006. Prosedur Operasional Standar Budidaya Kentang Varietas Granola (Solanum tuberosum L.) Kabupaten Bandung Propinsi Jawa Barat. Jakarta. Direktorat Budidaya Tanaman Sayuran dan Biofarmaka, Direktorat Jendral Hortikultura, Kementrian Pertanian Republik Indonesia.

Mulyono, L. 2016. Berbagai Macam Ukuran Plastik Polibag sebagai Referensi Budidaya TanamanHortikultura.http://www.polybag12 3.com/, 2 Juni 2017.

Oliveira, J.S. 2015. Growth and Development of Potato (Solanum tuberosum L.) Crops After Different Cool Season Storage. Lincoln University Digital Thesis, New Zealand.

Pracaya. 2007. Bertanam Sayuran Organik di Kebun, Pot dan Polibag. Penebar Swadaya, Jakarta.

Prahardini, P.E.R. dan G. Pratomo. 2011. Uji Adaptasi Varietas dan Klon Kentang Olahan Pada Musim Kemarau di Dataran Tinggi Beriklim Kering. Balai Pengkajian Teknologi Pertanian Jawa Timur.

Prematilake, D.P. 2005. Inducing Genetic Variation of Innala (Solanostemon rotundifolius) Via In Vitro Callus Culture. Journal National Science Foundation Sri Lanka 33 : 123-131.
Setiadi dan F.N. Surya. 2009. Kentang: Varietas dan Pembudidayaan. Penebar Swadaya, Jakarta.

Solin. 2009. Fisiologi Tanaman Budidaya. Universitas Indonesia, Jakarta.

Sunarjono, H. 2007. Petunjuk Praktis Budidaya Kentang. Agromedia Pustaka, Jakarta.

Survei Sosial Ekonomi Nasional. 2013. Buletin Konsumsi Pangan. Pusat Data dan Sistem Informasi Pertanian, Jakarta 1(4) : 1-53.

Wasonowati, C. 2011. Meningkatkan Pertumbuhan Tanaman Tomat (Lycopersicum esculentum Mill) dengan Sistem Budidaya Hidroponik. Agrovigor $4: 21-28$.

Wattimena, G.A.2000. Pengembangan Propagula Kentang Bermutu dan Kultivar Kentang Unggul dalam Mendukung Peningkatan Produksi Kentang di Indonesia. Orasi Ilmiah Guru Besar Tetap Hortikultura. Fakultas Pertanian. Institut Pertanian Bogor, Bogor.

Wiratama, A. 2016. Keunggulan Budidaya TanamanMenggunakanPolybag.http://www.s atujam.com/tanaman-polybag/. 17 Mei 2017.

Wulandari, A. 2012. Penggunaan Bobot Umbi Bibit pada Peningkatan Hasil Tanaman Kentang (Solanum tuberosum L.) G3 dan G4 Varietas Granola. Jurnal Produksi Tanaman 1 (2) : 65 68.

Zelelew, D.Z., Sewa, L., Tesfai, T.K., and Biniam, M.G. 2016. Effect of Potassium Levels on Growth and Productivity of Potato Varieties. American Journal of Plant Science 7 : 1629. 1638.

Zulfitri, I. 2015. Analisis Varietas dan Polibag terhadap Pertumbuhan serta Hasil Cabai (Capsicum annum L.) Sistem Hidroponik. Skripsi. Fakultas Pertanian Institut Pertanian Bogor, Bogor.

Zulkarnain. 2010. Dasar-dasar Hortikultura. Bumi Aksara, Jakarta 